\title{
Square Inch
}

National Cancer Institute

\section{Source}

National Cancer Institute. Square Inch. NCI Thesaurus. Code C68871.

A traditional unit of area equal to the area of a square with sides of one inch. It is equal to 6.4516 square centimeters. 